\title{
QSPR ANALYSIS OF A SET OF LIQUID CRYSTALS IN THE BENZYLIDENEANILINE CLASS ACCORDING TO THEIR TRANSITION TEMPERATURE
}

\author{
THOMAS DIPPONG ${ }^{a}$, ALEXANDRA AVRAM $^{\mathrm{b}}$, FIRUTA GOGA $^{\mathrm{b} *}$
}

\begin{abstract}
The present paper focuses on the connection amongst the structure of 25 liquid crystals in the benzylideneaniline class and some of their physico-chemical properties. Simple and multiple correlations between transition temperatures and 34 calculated molecular descriptors (25 topological indices and 12 Van der Waals parameters), for each compound, were made. Simple and multiple correlations amongst topological indices and Van der Waals parameters, respectively, observing the variations taking place, are presented.
\end{abstract}

Keywords: liquid crystals, benzylideneaniline, topological indices, Van de Waals parameters

\section{INTRODUCTION}

The microstructure of liquid crystals is complex and very variable. Some organic substances pass from crystaline, solid to isotropic, liquid states, not directly, but through a phase [1,2]. The mechanical and symmetrical properties of these phases are intermediate to the properties of liquids and crystals $[3,4]$. Because of this, these substances are called liquid crystals or liquid anisotropic crystals. Anisotropic liquids are characterized by a molecular order, which can be translational, rotational, or combinations of the two. The translational order is conditioned by the non-spherical or elongated shape of the molecules that make up the mesophase [5]. The molecular structure is a defining criterion in the categorization of mesophases as anisotropic liquids or liquid crystals [6].

\footnotetext{
a Technical University of Cluj-Napoca, Faculty of Sciences North University Center at Baia Mare, Department of Chemistry and Biology, 76 Victoriei Street, 430122 Baia Mare, Romania

b Babeş-Bolyai University, Faculty of Chemistry and Chemical Engineering, 11 Arany Janos Street., RO-400028, Cluj-Napoca, Romania

*Corresponding author: fgoga@chem.ubbcluj.ro
} 
According to Friedel $[7,8]$, three types, or groups of liquid crystals are distinguished: smectic, nematic and cholesteric, as well as discotic liquid crystals called columnar. The liquid crystals belonging to each of these groups are distinguished by their physical properties, primarily optical ones. These differences arise as a result of a difference in structure.

In smectic liquid crystals, molecules, elongated in the form of sticks, are arranged parallel to their length and form layers of equal thickness, close to the length of the molecules [9]. These layers are organized one above the other at equal distances. Molecular layers in typical smectics are mobile, moving slightly parallel to one another. The transition temperature in the mesomorphic state is quite high. This temperature must be of such value as to destroy the bond between the molecules placed at close distances. Distance between layers can be measured by X-ray diffraction [10].

In cholesteric liquid crystals, the molecules have an orientational ordering of the molecules of the long axis and the center of mass unordered formation, similar to the nematic, but in contrast to this the structure of the balance [11]. Cholesterol derivatives are part of this category, hence the name of the group of liquid crystals. In cholesteric liquid crystals molecules are arranged in layers, as in smectics, but the long axes are parallel to the layers' planes. The layers in the cholesteric liquid crystals are thin, monomolecular. The direction of the long axis orientation of the molecules in each layer is terminated with respect to the previous one, which leads to the formation of a spiral molecular structure $[9,11]$. Most cholesteric fluids are cholesterol derivatives, cholesteryl acetate, cholesteryl nitrate.

The nematic phase is characterized by long-range orientation [12], which means that long axes of molecules tend to move along the preferential axis. The nematic mesomorphic structure is characterized in that the orientation of the axes of the molecules in such crystals is parallel but does not form layers [13].

Liquid column crystals are different from previous shapes, the molecules are not elongated or discoidal in shape and the arrangement envolves an overlaping of the discs in the columns [14]. This mesophase is characterized by a packet of columns and molecules. The columns are wrapped together along the two surface crystalline dimensions. Arranging the molecules in columns leads to the formation of new mesophases $[15,16]$.

In technology, thin-film nematic crystals change their transmission properties for natural or polarized light when an electric field is applied $[17,18]$. It can be used for alphanumeric and analog display, image conversion, and matrix screens for image playback. In medicine, the use of cholesterolbased liquid crystals in skin thermography and diagnosis derives from the special optical properties of thin films of these substances that indicate 
rapidly and directly through their color [19]. In chemistry, nematic and cholesteric liquid crystals are very good solvents for organic molecules. They can be incorporated into liquid crystals in concentrations that do not damage the internal order of the liquid crystals. They are used for spectroscopic investigations of the anisotropic properties of molecules. Liquid crystals are used as solvents in ultraviolet-visible spectroscopy, magnetic resonance imaging, electronic spin resonance to obtain information on the length of solute molecule bonds $[20,16]$.

The present paper focuses on the connection amongst the structure of 25 liquid crystals in the benzylideneaniline class, molecules that fall into the nematic liquid crystals, and some of their physico-chemical properties. The polymers and coordination compounds in the benzylideneaniline class (with $\pi$ conjugate systems) are important optical functional compounds and have been applied extensively in the fields of liquid crystal materials [22]. Thus, we calculated and tested 34 molecular descriptors, of which 25 topological indices and 12 Van der Waals parameters.

\section{RESULTS AND DISCUTION}

The values of the $\mathrm{R}$ correlation coefficient that resulted from Pearson's linear correlation test, between the transition temperature and each of the 35 molecular descriptors are shown in Table 1. Relatively low correlations, both in regards to Van der Waals parameters - transition temperatures, and, topological indices - transition temperatures, in the case of liquid crystals in the benzylideneaniline compounds class, are noted.

The obtained coefficients, lower than $\mathrm{R}^{2}=0.4$, lead to weak correlations, almost insignificant when compared to previous studies (column liquid crystals), where correlations higher than 0.8 , with the same topological indices or Van der Waals parameters, were obtained.

The tracked Van der Waals parameters were: Van der Waals Molecular Volume $\left(\mathrm{V}^{\mathrm{w}}\right)$, van der Waals surface $\left(\mathrm{S}^{\mathrm{w}}\right)$, Van der Waals ratio $\left(\mathrm{VW}^{\mathrm{W}} / \mathrm{S}^{\mathrm{W}}\right)$, volume of the sphere $\left(\mathrm{VSF}^{\mathrm{SF}}\right)$, volume of the ellipsoid $(\mathrm{VEL})$, the ellipsoid semi-axes (EX, EY, EZ), the ratio between the volume of the sphere and the Van der Waals volume $\left(\mathrm{GL}_{1}\right)$, the ratio between the volume of the sphere and that of the ellipsoid $\left(\mathrm{GL}_{2}\right)$, the degree of volume globularity (GLOB, the ratio between the Van der Waals volume and that of the sphere) [23]. The used topological indices were as follows: Wiener $(W)$, polarity $(P)$, Gordon-Scantlebury Index $\left(\mathrm{N}_{2}\right)$, Zagreb $\left(\mathrm{M}_{1}\right.$ si $\left.\mathrm{M}_{2}\right)$, Randić $\left({ }^{1} \chi,{ }^{2} \chi,{ }^{3} \chi\right)$, Balaban $\left(\mathrm{J}_{2}, \mathrm{~J}_{3}\right)$, Balaban and Randić index with the covalent radii $\left(\mathrm{J}^{\mathrm{rc}}, \chi^{\mathrm{rc}}\right)$, Mulliken's electronegativities $\left(\mathrm{Jel}^{\mathrm{el}}, \chi^{\mathrm{el}}\right)$ and by Van der Waals radii $\left(\mathrm{J}^{\mathrm{Rw}}, \chi^{\mathrm{RW}}\right)$, Kier and 
Hall Indices $\left(\chi \mathrm{D}^{\mathrm{el}}, J \mathrm{~J}^{\mathrm{el}}\right.$ were calculated for Mulliken's electronegativities, the indices $\chi \mathrm{D}^{\mathrm{rc}}$ and $\mathrm{JD}{ }^{\mathrm{rc}}$ for the covalent radii, and, respectively, the indices $\chi D^{R w}, J D^{R w}$ for van der Waals radii) [23].

Table 1. Statistical parameters of the mono-variable regressions equations

\begin{tabular}{|c|c|c|c|c|c|}
\hline \multicolumn{3}{|c|}{ Van der Wals parameters } & \multicolumn{3}{|c|}{ Topological indices } \\
\hline \multirow[t]{2}{*}{$\begin{array}{l}\text { Independent } \\
\text { variable }\end{array}$} & \multicolumn{2}{|c|}{$\begin{array}{l}\text { Statistical } \\
\text { parameter }\end{array}$} & \multirow[t]{2}{*}{$\begin{array}{l}\text { Independent } \\
\text { variable }\end{array}$} & \multicolumn{2}{|c|}{$\begin{array}{c}\text { Statistical } \\
\text { parameters }\end{array}$} \\
\hline & $\mathbf{R}^{2}$ & $F$ & & $\mathbf{R}^{2}$ & $F$ \\
\hline $\mathrm{V}^{\mathrm{W}}$ & 0.442 & 7.72 & W & 0.354 & 6.55 \\
\hline $\mathrm{S}^{\mathrm{W}}$ & 0.446 & 7.89 & $P$ & 0.402 & 7.63 \\
\hline $\mathrm{V}^{\mathrm{W}} / \mathrm{S}^{\mathrm{W}}$ & 0.205 & 3.39 & $\mathrm{~N}_{2}$ & 0.431 & 7.60 \\
\hline $\mathrm{V}^{\mathrm{SF}}$ & 0.350 & 6.03 & M1 & 0.446 & 7.90 \\
\hline $\mathrm{S}^{\mathrm{SF}}$ & 0.501 & 9.14 & $\mathrm{M}_{2}$ & 0.436 & 7.70 \\
\hline $\mathrm{V}^{\mathrm{EL}}$ & 0.415 & 7.94 & ${ }^{1} \chi$ & 0.411 & 7.92 \\
\hline Ex & 0.400 & 16.94 & $\frac{\pi}{2 \gamma}$ & 0.321 & 6.09 \\
\hline EY & 0.206 & 4.39 & ${ }^{3} \chi$ & 0.394 & 6.64 \\
\hline Ez & 0.108 & 1.20 & $\chi^{\text {rc }}$ & 0.407 & 7.11 \\
\hline $\mathrm{GL}_{1}$ & 0.312 & 5.22 & $\chi^{\mathrm{el}}$ & 0.402 & 7.65 \\
\hline GL2 & 0.215 & 4.08 & $\chi^{\mathrm{Rw}}$ & 0.401 & 7.20 \\
\hline GLOB & 0.508 & 12.5 & $\chi \mathrm{D}^{r c}$ & 0.391 & 6.55 \\
\hline & & & $\chi \mathrm{D}^{\mathrm{el}}$ & 0.396 & 7.23 \\
\hline & & & $\chi \mathrm{D}^{\mathrm{Rw}}$ & 0.386 & 7.39 \\
\hline & & & J2 & 0.324 & 5.47 \\
\hline & & & J3 & 0.222 & 4.00 \\
\hline & & & $\mathrm{Jrc}^{\mathrm{rc}}$ & 0.055 & 0.13 \\
\hline & & & Jel & 0.068 & 0.12 \\
\hline & & & $J^{R w}$ & 0.006 & 0.001 \\
\hline & & & $J^{\prime r c}$ & 0.112 & 1.15 \\
\hline & & & $\mathrm{JD}^{\mathrm{el}}$ & 0.009 & 0.002 \\
\hline & & & $\mathrm{JD}^{\mathrm{Rw}}$ & 0.008 & 0.002 \\
\hline
\end{tabular}

As an example, the best' simple liniar correlations between temperature and $E_{X}$, and, transition temperature and globularity (GLOB), are rendered as a graph, where: $\mathrm{R}^{2}$ - coefficient of determination SE - standard error, MSE - Mean Square error.

$$
\begin{aligned}
T_{z} & =-70.06+15.05 E X \\
R^{2}=0.400 \quad S E & =33.34 \quad F=16.94 \quad M S E=146.14
\end{aligned}
$$




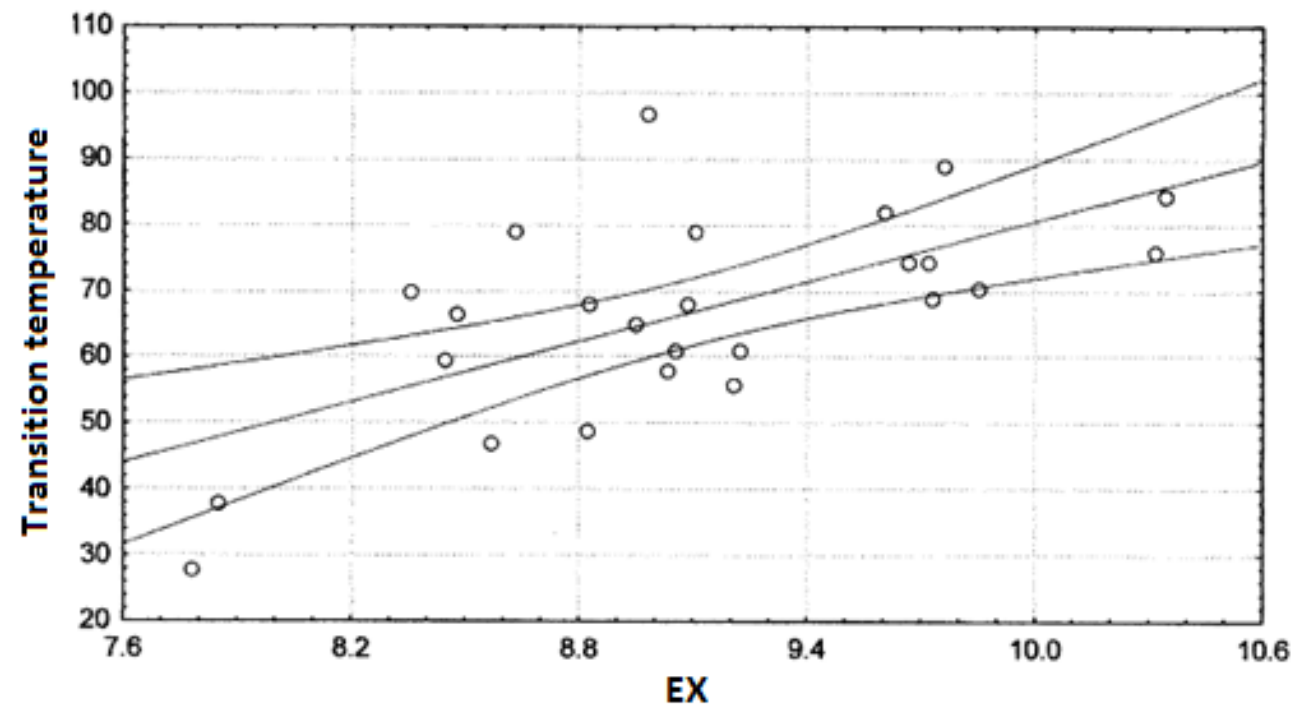

Figure 1. Correlation between the transition temperature and Ex

$$
\begin{aligned}
\mathrm{T}_{z} & =167.16-384.23 \quad \mathrm{GLOB} \\
\mathrm{R}^{2}=0.508 \quad \mathrm{SE} & =28.49 \quad \mathrm{~F}=12.5 \quad \mathrm{MSE}=164.4
\end{aligned}
$$

Eliminating the values located outside the confidence interval (the two curves), even if, the statistical parameters would improve, is not recomended, as, the application generality of the ontained result would diminish.

As can be seen, the correlation between the tranition temperature and the Van der Waals ratio $\left(\mathrm{V}^{\mathrm{W}} / \mathrm{S}^{\mathrm{W}}\right)$ presents very week correlations, even lower than those between separates of the Van der Waals volume $\left(R^{2}=0.442\right)$ and Van der Waals surface $\left(R^{2}=0.446\right)$, the vapor dispersion being a lot higher.

$$
\begin{aligned}
\mathrm{T}_{z} & =5.45+0.17 \mathrm{VW} \\
\mathrm{R}^{2}=0.442 \quad \mathrm{SE} & =22.25 \quad \mathrm{~F}=7.73 \quad \mathrm{MSE}=189.9 \\
\mathrm{~T}_{z} & =2.30+0.227 \mathrm{~S} w \\
\mathrm{R}^{2}=0.446 \quad \mathrm{SE} & =23.13 \quad \mathrm{~F}=7.89 \quad \mathrm{MSE}=188.9 \\
\mathrm{~T}_{z} & =872.99-1011.61 \mathrm{VW} / \mathrm{S}^{\mathrm{W}} \\
\mathrm{R}^{2}=0.205 \quad \mathrm{SE} & =22.1123 \quad \mathrm{~F}=3.39 \quad \mathrm{MSE}=221.11
\end{aligned}
$$


In case of correlating the surface of the $S^{S F}$ sferoid, a better correlation can be obtained $\left(R^{2}=0.501\right)$, but weeker than in the case of globularity $\left(R^{2}=0.508\right)$.

$$
\begin{aligned}
& \mathrm{T}_{\mathrm{z}}=29.018-0.034 \mathrm{~S}^{\mathrm{SF}} \\
& \mathrm{R}^{2}=0.501 \quad \mathrm{SE}=12.82 \quad \mathrm{~F}=9.10 \quad \mathrm{MSE}=181.81
\end{aligned}
$$

In these calculations we find the multiple correlation coefficient $\mathrm{R}^{2}$ (which for a good correlation should tend to the value of $1, F$ (the Fisher test value) which, for the statistical significance of correlations, is desired to be as high as possible. $S$ is the explained variance, a statistical indicator commonly used in the study of structure-property relationships as it shows what percentage of the property being analyzed is explained by the variables used in a correlation.

In the case of correlations of transition temperatures with topological indices, low correlation coefficients are also obtained, usually between 0.3$0.45,{ }^{2} \chi$, presenting the best correlation of this class of compounds.

$$
\begin{aligned}
T_{z} & =12.776+6.872^{2} \chi \\
R^{2}=0.321 \quad S E & =22.07 \quad F=6.09 \quad M S E=200.59
\end{aligned}
$$

Other correlations with over 0.5 were obtained in the case of the correlation between the transition temperature and Gordon (N2), M1, M2 and J3.

$$
\begin{aligned}
& \mathrm{T}_{\mathrm{z}}=-21.420+3.420 \mathrm{~N} 2 \\
& R^{2}=0.431 \quad S E=32.11 \quad F=7.60 \quad M S E=190.69 \\
& \mathrm{~T}_{\mathrm{z}}=-25.752+0.948 \mathrm{M} 1 \\
& \mathrm{R}^{2}=0.446 \quad \mathrm{SE}=33.05 \quad \mathrm{~F}=7.90 \quad \mathrm{MSE}=188.88 \\
& \mathrm{~T}_{\mathrm{z}}=-33.689+0.932 \mathrm{M} 2 \\
& \mathrm{R}^{2}=0.436 \quad \mathrm{SE}=36.32 \quad \mathrm{~F}=7.70 \quad \mathrm{MSE}=190.11 \\
& \mathrm{~T}_{\mathrm{z}}=68.023-0.119 \mathrm{~J} 3 \\
& \mathrm{R}^{2}=0.222 \quad \mathrm{SE}=3.00 \quad \mathrm{~F}=4.00 \quad \mathrm{MSE}=216.14
\end{aligned}
$$

Several multilinar correlations have been made, trying to find those descriptors that are not interleaved and, thus, increase the correlation coefficient. The best result was obtained by the multilinear correlation of the 
transition temperature with the topological indices and Van der Waals parameters. Thus, by correlating the transition temperature and ${ }^{2} \chi,{ }^{3} \chi$, Jel, JD ${ }^{\mathrm{rc}}, \mathrm{N} 2$ (equation 12 ), a $R^{2}$ of 0.720 is obtained, compared to very low coefficients obtained separately.

$$
\begin{array}{r}
T_{z}=-782.42+144.9^{2} \chi-177.8^{3} \chi+10185.4 \mathrm{Jel}^{\mathrm{el}}-1119.2 \mathrm{JD}^{\mathrm{rc}}-13.37 \mathrm{~N} 2 \\
\mathrm{R}^{2}=0.720 \quad \mathrm{SE}=15.86 \quad \mathrm{~F}=10.49 \quad \mathrm{MSE}=100.31
\end{array}
$$

Taking into account the method of calculating the topological indices, we find that the ${ }^{2} \chi$ şi $\mathrm{J}^{\mathrm{el}}$ ones are favorable to the increase of the transition temperature, therefore, there is a flexibility component [Kier and Hall [24]] and a favorable electronic one ( $\mathrm{Jl}$ is the index $\mathrm{J}$ calculated for atomic electronegativity). In the case of the above set, the ${ }^{2} \chi$ şi $^{3} \chi$ indices are intercorrelated.

Only by correlating the transition temperature with the randic and balaban indices, does the $\mathrm{R}^{2}$ correlation coefficient decrease.

$$
\begin{array}{r}
T_{z}=-1722+86.91 \chi^{e l}+407022 J^{R w}-225149 \mathrm{Jrc}^{\mathrm{rc}}-936228 \mathrm{~J} \\
\mathrm{R}^{2}=0.704 \quad \mathrm{SE}=12.63 \quad \mathrm{~F}=6.72 \quad \mathrm{MSE}=108.45
\end{array}
$$

As randic indices encode information about the size and branching of molecules, it is interesting to see what happens if the mentioned indices are replaced by the van der Waals report, thus, obtaining function 14 .

$$
\begin{array}{r}
T_{z}=-7196+8997 \mathrm{VW}^{\mathrm{w}} / \mathrm{S}^{\mathrm{W}}-1270 \mathrm{~J} 2-184124 \mathrm{~J} 3-225.7 \mathrm{Jel} \\
\mathrm{R}^{2}=0.615 \quad \mathrm{SE}=15.34 \quad \mathrm{~F}=4.41 \quad \mathrm{MSE}=121.29
\end{array}
$$

There is a decrease in the correlation coefficient at 0.615 , which denotes an inverse effect from that of the column liquid crystals, where there was an increase in the correlation coefficient following the involvement of the Van der Waals report [23].

A main purpose of QSPR is to detect a mathematical link between the surveyed property and the molecular descriptors derived from the structure of the molecule [25].

Opposed to columnar liquid crystals [23], liquid crystals from the benzylideneaniline group present weaker mathematical models. It can be concluded that the liniar chemical structure of these compounds is not that stable when compared to the branched one of columnar liquid crystals. 


\section{CONCLUSIONS}

The information obtained from the molecules of the benzylideneanilide liquid crystals is insufficient, as the property taken into account also depends on other factors not covered by the considered molecular descriptors. These molecules fall into the nematic liquid crystals, which have the main characteristic of orienting themselves along a straight line called a steering axis, being formed by relatively long molecules without distinct branches. This is also evident from the fact that the best correlation is given by the Ex transition $\left(R^{2}=0.40\right)$, a ratio that can be assimilated in a first approximation with a length. It is assumed that other parameters such as the average angle of the molecules with the reference axis, the degree of ordering and a series of parameters describing the intermolecular interactions of physical nature (electrostatic) taking into account the polarity of the compounds can be considered. Although the correlation between the transition temperature and Van der Waals parameters, respectively topological indices, give lower correlation coefficients than with column liquid crystals. If multiple correlations are achieved, higher correlation coalescients are obtained. This study is very important as it takes a new, unique approach in regards to the structure of liquid crystals in the benzylideneaniline class and the correlation degree between transition temperature, topological indices and Van der Waals parameters, respectively. An improvement upon mathematical models as a result of multiple regresions between transition temperature - topological indices - Van der Waals parameters can also be observed.

\section{EXPERIMENTAL SECTION}

The used method of determining the liquid crystal transition temperature allows a highlight of the type of texture, the type of phase, and the transition temperature of the liquid crystal samples using the polarizing microscope. Study cells contain nematic crystals (4-cyano-phenyl-4pentylbenzoate). Each cell is made of glass walls on which a transparent conductive layer of $\ln _{2} \mathrm{O}_{3}$ has been deposited. Measurements require the use of a heating device and a one for stabilizing and measuring the temperature. As heating device, an aluminum electric furnace having dimensions of $5 \times 6 \mathrm{~cm}^{2}$ and $1 \mathrm{~cm}$ thickness, was used. Heating of the furnace is made by means of an electrical resistance, the heating current being controlled by the temperature stabilizer. The furnace is provided with a seat for fixing the sample. The temperature transducer that fits through a furnace inlet and has its ends connected to the temperature-determining device is fixed on the cell. The 
furnace has outputs for supplying the electrical resistance, allowing the application of an electric field to the samples. Both the furnace and lid are equipped with windows for visualising samples and optical measurements. After the sample has been placed inside, the furnace is connected to the microscope and heated to $70-80^{\circ} \mathrm{C}$.<smiles>[R1]Oc1ccc(C=Nc2ccc([R2])cc2)cc1</smiles>

Figure 4. General structure of the benzylideneaniline class

Table 2. The most important reprezentatives of the benzylideneaniline class

\begin{tabular}{|l|l|l|l|}
\hline Comp. & \multicolumn{1}{|c|}{$\mathbf{R} 1$} & $\mathbf{R} 2$ & Ttransition \\
\hline t01 & $\mathrm{CH}_{3}$ & $\mathrm{CH}_{3}$ & 38 \\
t02 & $\mathrm{C}_{2} \mathrm{H}_{5}$ & $\mathrm{CH}_{3}$ & 79 \\
t03 & $\mathrm{C}_{3} \mathrm{H}_{7}$ & $\mathrm{CH}_{3}$ & 49 \\
t04 & $\mathrm{C}_{4} \mathrm{H}_{9}$ & $\mathrm{CH}_{3}$ & 68 \\
t05 & $\mathrm{C}_{5} \mathrm{H}_{11}$ & $\mathrm{CH}_{3}$ & 58 \\
t06 & $\mathrm{CH}_{3}$ & $\mathrm{C}_{2} \mathrm{H}_{5}$ & 28 \\
t07 & $\mathrm{C}_{2} \mathrm{H}_{5}$ & $\mathrm{C}_{2} \mathrm{H}_{5}$ & 70 \\
t08 & $\mathrm{C}_{3} \mathrm{H}_{7}$ & $\mathrm{C}_{2} \mathrm{H}_{5}$ & 66,5 \\
t09 & $\mathrm{C}_{4} \mathrm{H}_{9}$ & $\mathrm{C}_{2} \mathrm{H}_{5}$ & 65 \\
t10 & $\mathrm{C}_{5} \mathrm{H}_{11}$ & $\mathrm{C}_{2} \mathrm{H}_{5}$ & 61 \\
t11 & $\mathrm{CH}_{3}$ & $\mathrm{C}_{3} \mathrm{H}_{7}$ & 59,5 \\
t12 & $\mathrm{C}_{2} \mathrm{H}_{5}$ & $\mathrm{C}_{3} \mathrm{H}_{7}$ & 97 \\
t13 & $\mathrm{C}_{3} \mathrm{H}_{7}$ & $\mathrm{C}_{3} \mathrm{H}_{7}$ & 68 \\
t14 & $\mathrm{C}_{4} \mathrm{H}_{9}$ & $\mathrm{C}_{3} \mathrm{H}_{7}$ & 82 \\
t15 & $\mathrm{C}_{5} \mathrm{H}_{11}$ & $\mathrm{C}_{3} \mathrm{H}_{7}$ & 74,5 \\
t16 & $\mathrm{CH}_{3}$ & $\mathrm{C}_{4} \mathrm{H}_{9}$ & 47 \\
t17 & $\mathrm{C}_{2} \mathrm{H}_{5}$ & $\mathrm{C}_{4} \mathrm{H}_{9}$ & 79 \\
t18 & $\mathrm{C}_{3} \mathrm{H}_{7}$ & $\mathrm{C}_{4} \mathrm{H}_{9}$ & 56 \\
t19 & $\mathrm{C}_{4} \mathrm{H}_{9}$ & $\mathrm{C}_{4} \mathrm{H}_{9}$ & 74,5 \\
t20 & $\mathrm{C}_{5} \mathrm{H}_{11}$ & $\mathrm{C}_{4} \mathrm{H}_{9}$ & 69 \\
t21 & $\mathrm{CH}_{3}$ & $\mathrm{C}_{5} \mathrm{H}_{11}$ & 61 \\
t22 & $\mathrm{C}_{2} \mathrm{H}_{5}$ & $\mathrm{C}_{5} \mathrm{H}_{11}$ & 89 \\
t23 & $\mathrm{C}_{3} \mathrm{H}_{7}$ & $\mathrm{C}_{5} \mathrm{H}_{11}$ & 70,5 \\
t24 & $\mathrm{C}_{4} \mathrm{H}_{9}$ & $\mathrm{C}_{5} \mathrm{H}_{11}$ & 84,5 \\
t25 & $\mathrm{C}_{5} \mathrm{H}_{11}$ & $\mathrm{C}_{5} \mathrm{H}_{11}$ & 76 \\
\hline
\end{tabular}


When this temperature is reached, the heating system is decoupled and monitored during sample cooling: the temperature at which the crystal transitions from the liquid state to the mesophase (transition temperature), the transition temperature $F$, the solid state and the type of texture that occurs in this phase.

The results of the simple linear correlations of the transition temperatures with the calculated molecular descriptors are presented in the following tables, the first column being the independent variable (topological index or Van der Waals parameter), the second, the R correlation coefficient (which, for good correlation, must tend to to the value of 1 ) and, in the third column, is the Fisher test value for the statistical significance of the correlations, which is desirable to be as high as possible. All formulas were drawn in the Hyperchem program, then optimized by molecular modeling, calculating free energies. In order to refine the calculations, an ab initio calculation was chosen, as, in the ab initio variants, the different energy components of the molecules, including the electron-based component, can be calculated. Topological indices and Van der Waals parameters were calculated using the formulas mentioned above. Linear and multiple correlations were performed with Statistics 7.0 and OriginPro8.

Table 3. Topological indices for benzylideneanilines

\begin{tabular}{|c|c|c|c|c|c|c|c|c|c|c|c|}
\hline Nr & $\mathbf{W}$ & $\mathbf{P}$ & $\mathbf{N 2}$ & $\mathbf{M} 1$ & $\mathbf{M} 2$ & ${ }^{1} \chi$ & ${ }^{2} \chi$ & ${ }^{3} \chi$ & $\mathbf{J}$ & J2 & J3 \\
\hline b1 & 616 & 40 & 21 & 82 & 91 & 8.28 & 6.42 & 3.85 & 1.59 & 0.23 & 0,0251 \\
\hline b2 & 733 & 43 & 22 & 86 & 95 & 8.78 & 6.80 & 4.22 & 1.57 & 0.21 & 0.0227 \\
\hline b3 & 872 & 45 & 23 & 90 & 99 & 9.28 & 7.15 & 4.49 & 1.55 & 0.20 & 0.02 \\
\hline b4 & 1030 & 46 & 24 & 94 & 103 & 9.78 & 7.51 & 4.58 & 1.53 & 0.18 & 0.017 \\
\hline b5 & 1208 & 48 & 25 & 98 & 107 & 10.28 & 7.86 & 4.83 & 1.50 & 0.17 & 0.0149 \\
\hline b6 & 729 & 42 & 23 & 86 & 96 & 8.81 & 6.59 & 3.97 & 1.58 & 0.22 & 0.0225 \\
\hline b7 & 864 & 44 & 24 & 90 & 100 & 9.31 & 6.97 & 4.18 & 1.57 & 0.20 & 0.0199 \\
\hline b8 & 1018 & 46 & 25 & 94 & 104 & 9.81 & 7.32 & 4.45 & 1.55 & 0.19 & 0.0176 \\
\hline b9 & 1192 & 48 & 26 & 98 & 108 & 10.31 & 7.68 & 4.70 & 1.53 & 0.18 & 0.0155 \\
\hline b10 & 1387 & 50 & 27 & 102 & 112 & 10.81 & 8.03 & 4.95 & 1.50 & 0.16 & 0.0138 \\
\hline b11 & 864 & 44 & 24 & 90 & 100 & 11.31 & 6.97 & 4.18 & 1.57 & 0.20 & 0.0201 \\
\hline b12 & 1014 & 46 & 25 & 94 & 104 & 9.81 & 7.35 & 4.38 & 1.55 & 0.19 & 0.0179 \\
\hline b13 & 1184 & 48 & 26 & 98 & 108 & 10.31 & 7.70 & 4.65 & 1.54 & 0.18 & 0.0159 \\
\hline b14 & 1375 & 50 & 27 & 102 & 112 & 10.81 & 8.06 & 4.90 & 1.52 & 0.17 & 0.0142 \\
\hline b15 & 1588 & 52 & 28 & 106 & 116 & 11.31 & 8.41 & 5.15 & 1.50 & 0.16 & 0.0127 \\
\hline b16 & 1018 & 46 & 25 & 94 & 104 & 11.81 & 7.32 & 4.45 & 1.55 & 0.19 & 0.018 \\
\hline b17 & 1184 & 48 & 26 & 98 & 108 & 10.31 & 7.70 & 4.65 & 1.54 & 0.18 & 0.0161 \\
\hline b18 & 1317 & 50 & 27 & 102 & 112 & 10.81 & 8.06 & 4.92 & 1.52 & 0.17 & 0.0144 \\
\hline b19 & 1580 & 52 & 28 & 106 & 116 & 11.31 & 8.41 & 5.17 & 1.51 & 0.16 & 0.0129 \\
\hline b20 & 1812 & 54 & 29 & 110 & 120 & 11.81 & 8.76 & 5.42 & 1.49 & 0.15 & 0.0116 \\
\hline b21 & 1192 & 48 & 26 & 90 & 108 & 10.31 & 7.68 & 4.70 & 1.53 & 0.18 & 0.016 \\
\hline b22 & 1375 & 50 & 27 & 102 & 112 & 10.81 & 8.06 & 4.90 & 1.52 & 0.17 & 0.0145 \\
\hline b23 & 1580 & 52 & 28 & 106 & 116 & 11.31 & 8.41 & 5.17 & 1.51 & 0.16 & 0.013 \\
\hline b24 & 1808 & 54 & 29 & 110 & 120 & 11.81 & 10.38 & 5.42 & 1.49 & 0.15 & 0.0118 \\
\hline b25 & 2060 & 56 & 30 & 114 & 124 & 12.31 & 10.97 & 5.67 & 1.48 & 0.14 & 0.0106 \\
\hline
\end{tabular}


QSPR ANALYSIS OF A SET OF LIQUID CRYSTALS IN THE BENZYLIDENEANILINE CLASS ...

Table 4. Van der Waals parameters for benzylideneanilines

\begin{tabular}{|c|c|c|c|c|c|c|c|c|c|c|c|}
\hline & $\mathbf{s}^{w}$ & $\mathbf{V}^{\mathbf{w}}$ & $\mathbf{V}^{\mathrm{SF}}$ & $\mathbf{S}^{\mathrm{SF}}$ & $V^{E L}$ & Ex & Ey & Ez & GLOB & GL1 & $\mathbf{v}^{\mathrm{w}} / \mathbf{S}^{\mathrm{w}}$ \\
\hline b1 & 215.2 & 266.4 & 2024.7 & 774.0 & 645.1 & 7.8 & 6.7 & 2.9 & 0.31 & 0.32 & 0.81 \\
\hline b2 & 232.6 & 289.0 & 2692.7 & 936.0 & 695.1 & 8.6 & 6.6 & 2.9 & 0.28 & 0.26 & 0.81 \\
\hline b3 & 250.0 & 310.7 & 2875.0 & 977.8 & 761.2 & 8.8 & 7.1 & 2.9 & 0.27 & 0.26 & 0.80 \\
\hline b4 & 267.1 & 333.1 & 2881.8 & 979.3 & 923.0 & 8.8 & 8.6 & 2.9 & 0.27 & 0.32 & 0.80 \\
\hline b5 & 283.3 & 355.7 & 321.7 & 1053.4 & 1005.5 & 9.0 & 9.1 & 2.9 & 0.26 & 3.13 & 0.79 \\
\hline b6 & 233.4 & 290.9 & 1973.3 & 760.8 & 928.3 & 7.8 & 7.3 & 3.9 & 0.31 & 0.47 & 0.80 \\
\hline b7 & 249.4 & 312.8 & 2443.9 & 877.4 & 1055.5 & 8.4 & 7.8 & 3.9 & 0.29 & 0.43 & 0.79 \\
\hline b8 & 267.0 & 334.9 & 2552.9 & 903.3 & 1169.1 & 8.5 & 8.5 & 3.9 & 0.28 & 0.46 & 0.79 \\
\hline b9 & 283.5 & 356.7 & 3073.5 & 1022.3 & 1266.5 & 8.9 & 9.0 & 3.7 & 0.26 & 0.41 & 0.79 \\
\hline b10 & 300.5 & 378.5 & 3735.6 & 1164.3 & 1392.6 & 9.0 & 9.6 & 3.8 & 0.25 & 0.37 & 0.79 \\
\hline b11 & 250.2 & 313.0 & 2522.8 & 896.2 & 1069.9 & 8.4 & 7.8 & 3.9 & 0.28 & 0.42 & 0.8 \\
\hline b12 & 267.4 & 334.9 & 3032.3 & 1013.1 & 1189.1 & 8.9 & 8.4 & 3.8 & 0.27 & 0.39 & 0.79 \\
\hline b13 & 283.5 & 356.8 & 3138.9 & 1036.7 & 1299.9 & 9.1 & 8.9 & 3.8 & 0.26 & 0.41 & 0.79 \\
\hline b14 & 301.5 & 378.9 & 3710.6 & 1159.1 & 1459.3 & 9.6 & 9.5 & 3.8 & 0.25 & 0.39 & 0.79 \\
\hline b15 & 318.1 & 401.3 & 4347.2 & 1288.1 & 1576.5 & 9.6 & 18.1 & 3.8 & 0.24 & 0.36 & 0.79 \\
\hline b16 & 266.8 & 334.9 & 2633.3 & 922.1 & 1269.4 & 8.6 & 8.3 & 4.2 & 0.28 & 0.48 & 0.79 \\
\hline b17 & 285.7 & 356.8 & 3161.2 & 1841.7 & 1419.8 & 9.1 & 8.8 & 4.2 & 0.26 & 0.45 & 0.8 \\
\hline b18 & 300.4 & 378.9 & 3478.0 & 1110.1 & 1522.4 & 9.2 & 9.4 & 4.2 & 0.25 & 0.44 & 0.79 \\
\hline b19 & 318.6 & 400.8 & 4164.3 & 1251.7 & 1705.5 & 9.7 & 9.9 & 4.2 & 0.24 & 0.41 & 0.79 \\
\hline b20 & 333.9 & 422. & 4925.6 & 1399.9 & 1780 & 9.7 & 10.5 & 4.1 & 0.23 & 0.36 & 0.79 \\
\hline b21 & 282.6 & 356.9 & 3281.5 & 1067.9 & 1463.4 & 9.2 & 8.6 & 4.4 & 0.26 & 0.45 & 0.79 \\
\hline b22 & 301.6 & 379.1 & 3894.9 & 1197.1 & 1631.0 & 9.7 & 9.1 & 4.4 & 0.24 & 0.42 & 0.79 \\
\hline b23 & 316.6 & 400.3 & 4006.2 & 1219.8 & 1176.5 & 9.8 & 9.8 & 4.4 & 0.24 & 0.29 & 0.79 \\
\hline b24 & 334.1 & 423.6 & 4696.9 & 1356.3 & 1936.2 & 10. & 10.4 & 4.3 & 0.23 & 0.41 & 0.79 \\
\hline b25 & 352.6 & 445.7 & 5531.3 & 1512.5 & 2002.7 & 10.3 & 10.9 & 4.2 & 0.22 & 0.36 & 0.79 \\
\hline
\end{tabular}

\section{REFERENCES}

1. A. Dequidt, P. Oswald, The European Physical Journal E, 2007, 24, 157.

2. Y. Chen, F. Peng, T. Yamaguchi, X. Song, S-T. Wu, Crystals, 2013, 3, 483.

3. C.-F. Dascalu, B.C. Zelinschi, D. Ortansa Dorohoi, Annals of ,Dunarea de jos' University of Galati, Fascicle II, 2011, 46.

4. S. Ermakov, A. Beletskii, O. Eismont, V. Nikolaev, Liquid Crystals in Biotribology (Biological and Medical Physics, Biomedical Engineering), Springer International Publishing, 2016, Chapter 2: Brief review of liquid crystals.

5. S. Chandrasekhar, B.K. Sadashiva, K.A. Suresh, Pramana, 1977, 9, 471.

6. G.H. Brown, Journal of Chemical Education, 1983, 60, 900.

7. S. Chandrasekhar, "Liquid Crystals", Cambridge University Press, 1992. 
8. D. Demus, J.W.G. Goodby, G.W. Gray, H.W. Spiess, "Handbook of Liquid Crystals", Wiley- $\mathrm{VCH}, 1998$.

9. D. Andrienko, Journal of Molecular Liquids, 2018, in press, https://doi.org/10.1016/j.molliq.2018.01.175.

10. A. Alvarez fernandez, P.H.J. Kouwer, International Journal of Molecular Sciences, 2016, 17, 731.

11. M.R. Alcantara, E.G. Fernandes, Journal of Physiscs, 2002, 2, 32.

12. S. Yilmaz, H. Melik, F. Angay, M. Emek, A. Yildirim, Journal of Modern Physics, 2011, 2, 248.

13. H. Ozbek, S. Ustunel, E. Kutlu, M.C. Cetinkaya, Journal of Molecular Liquids, 2014, 199, 275.

14. H. Bock, Columnar Liquid Crystals, 2001, 355.

15. A. Shulty, S. Diele, S. Laschat, "Novel columnar tetraphenylethenes", Tehnische Universitat Braunschweig, 1998.

16. E. Westphal, M. Prehm, I.H, Bechtold, C Tschierskeb, H, Gallardo, Journal of Materials Chemistry C, 2013, 1, 8011.

17. L.A. Bulavin, L.N. Lisetski, S.S. Minenko, A.N. Samoilov, V.V. Klepko, S.I. Bohvan, N.I. Lebovka, Journal of Molecular Liquids, 2017, in press, https://doi.org/10.1016/j.molliq.2017.12.078.

18. S.M. Kelly, M. O'Neill, Handbook of Advanced Electronic and Photonic Materials and Devices, edited by H.S. Nalwa, Volume 7: Liquid Crystals, Display and Laser Materials, Chapter 1, Academic Press, 2000.

19. I. Abdulhalim, R. Moses, R. Sharon, Acta Physica Polonica A, 2007, 112, 715.

20. B. Stevensson, A.Marini, H. Zimmermann, A. Maliniak, Journal of Physical Chemistry B, 2011, 115, 7561.

21. E. Westphal, M. Prehm, I.H, Bechtold, C Tschierskeb, H, Gallardo Journal of Materials Chemistry C, 2013, 1, 8011.

22. L. Wang, C. Cao, C. Cao, Journal of Physical Organic Chemistry, 2014, 27, https://doi.org/10.1002/poc.3341.

23. Z. Berinde, T. Dippong, C. Butean, Studia UBB Chemia, 2016, 61, 51.

24. L.B. Kier, L.H. Hall, "Molecular Connectivity in Chemistry and Drug Research", Acad. Press, 1976.

25. J.H. Al-Fahemi, Liquid Crystals, 2014, 41, 1575. 